\title{
The Preparation of Alumina Particles Wrapped in Few-layer Graphene Sheets and Their Application to Dye-sensitized Solar Cells
}

\author{
Kwang-Soon Ahn, Sang-Won Seo, Jeong-Hyun Park, Bong-Ki Min, ${ }^{\dagger}$ and Woo-Sik Jung* \\ School of Chemical Engineering, College of Engineering, Yeungnam University, Gyongsan 712-749, Korea \\ *E-mail: wsjung@yu.ac.kr \\ ${ }^{\dagger}$ Center for Research Utilities, Yeungnam University, Gyongsan 712-749, Korea \\ Received December 2, 2010, Accepted March 21, 2011
}

\begin{abstract}
Alumina particles wrapped in few-layer graphene sheets were prepared by calcining aluminum nitride powders under a mixed gas flow of carbon monoxide and argon. The graphene sheets were characterized by powder Xray diffraction (XRD), Raman spectroscopy, electron energy loss spectroscopy, and high-resolution transmission electron microscopy. The few-layer graphene sheets, which wrapped around the alumina particles, did not exhibit any diffraction peaks in the XRD patterns but did show three characteristic bands (D, G, and 2D bands) in the Raman spectra. The dye-sensitized solar cell (DSSC) with the alumina particles wrapped in fewlayer graphene sheets exhibited significantly improved overall energy-conversion efficiency, compared to conventional DSSC, due to longer electron lifetime.
\end{abstract}

Key Words : Graphene sheets, Aluminum nitride, Carbon monoxide, Dye-sensitized solar cell

\section{Introduction}

Since the first report on electrical properties of single layer graphene by Novoselov and Geim in 2004, ${ }^{1}$ graphene, a one-atom-thick planar sheet of $\mathrm{sp}^{2}$-bonded carbon atoms densely packed in a two-dimensional honeycomb crystal lattice, has attracted considerable interest because of its unique physical, chemical, and mechanical properties. ${ }^{2-5}$ However, the preparation of graphene sheets remains challenging. The main preparation methods reported so far are micromechanical cleavage of bulk graphite, ${ }^{1,2}$ graphite oxidation-exfoliation-reduction, ${ }^{4-9}$ ultrahigh vacuum graphization of silicon carbide, ${ }^{10,11}$ plasma enhanced chemical vapor deposition using methane as the carbon source, ${ }^{12}$ and substrate-free gas-phase synthesis using a microwave plasma reactor. ${ }^{13}$ In recent years, we prepared graphene sheets by the reduction of $\mathrm{CO}$ by aluminum sulfide $\left(\mathrm{Al}_{2} \mathrm{~S}_{3}\right)^{14,15}$

In this present work, we show another method for synthesis of graphene sheets by using $\mathrm{CO}$ gas which is reduced by aluminum nitride (AIN) powders. The reaction of $\mathrm{CO}$ with AIN is the reverse reaction of the carbothermal reduction and nitridation $(\mathrm{CRN})$ reaction of alumina $\left(\mathrm{Al}_{2} \mathrm{O}_{3}\right)$. The $\mathrm{CRN}$ reaction is expressed as follows:

$$
\mathrm{Al}_{2} \mathrm{O}_{3}(\mathrm{~s})+3 \mathrm{C}(\mathrm{s})+\mathrm{N}_{2}(\mathrm{~g}) \rightarrow 2 \mathrm{AlN}(\mathrm{s})+3 \mathrm{CO}(\mathrm{g})
$$

The CRN method is one of the most useful methods to synthesize AlN powders. ${ }^{16}$ The graphene sheets prepared in this work were characterized by powder X-ray diffraction (XRD), Raman spectroscopy, electron energy loss spectroscopy (EELS), and high-resolution transmission electron microscopy (HRTEM). The characterization revealed few-layer graphene sheets wrapped around alumina particles, which were applied to dye-sensitized solar cells (DSSCs) based on mesoporous $\mathrm{TiO}_{2}$ layers. DSSCs have been extensively studied as a low-cost alternative to commercial, silicon-based solar cells. ${ }^{17,18}$ However, the DSSCs have yet to be improved and their major bottleneck is directly related to large recombination rate, because the mesoporous $\mathrm{TiO}_{2}$ films composed of the nanoparticles smaller than $30 \mathrm{~nm}$ don't develop a depletion layer at the interface between the $\mathrm{TiO}_{2}$ and electrolyte, leading to large back electron transfer. ${ }^{19,20}$ It has recently been reported that the graphene in the mesoporous $\mathrm{TiO}_{2}$ electrodes benefits the charge separation and reduces the recombination rate, because it is a zero band gap material with electrons acting massless relativistic particles, so it provides an excellent electrical pathway. ${ }^{21,22}$

\section{Experimental Section}

Preparation of Alumina Particles Wrapped in Graphene Sheets. The AlN powders were prepared by calcining a (hydroxo)(succinato)Al(III) complex at $1300{ }^{\circ} \mathrm{C}$ for $5 \mathrm{~h}$ under a flow of nitrogen. ${ }^{23}$ The powders in an alumina crucible were set in an alumina tube with an inner diameter of $36 \mathrm{~mm}$ and heated at a rate of $5{ }^{\circ} \mathrm{C} / \mathrm{min}$ to $1400{ }^{\circ} \mathrm{C}$ in a gas mixture of argon and $10 \mathrm{vol} \% \mathrm{CO}$ (hereafter referred to as $10 \mathrm{vol} \% \mathrm{CO} / \mathrm{Ar}$ ) at a flow rate of $200 \mathrm{~mL} / \mathrm{min}$. The assynthesized products were characterized by powder XRD (PANalytical X'Pert PRO MPD X-ray diffractometer with $\mathrm{Cu}-\mathrm{K} \alpha$ radiation operating at $40 \mathrm{kV}$ and $30 \mathrm{~mA}$ ). The carbon content in the products was determined by a CHN elemental analyzer (Flash 1112, Thermo Fischer Scientific). Raman spectra were measured using a home-built microRaman system. The incident laser light of a He-Ne laser $(632.8 \mathrm{~nm}$, $3 \mathrm{~mW}$ ) was focused on the sample through an objective $(\times 100, \mathrm{NA}=0.7)$. The Raman scattered light was collected by the same objective and sent to the spectrometer. The acquisition time of each spectrum was $1 \mathrm{~min}$. A Cs-corrected 
Hitachi HD-2700 scanning transmission electron microscope equipped with a Gatan Imaging Filter was used to measure the HRTEM images and EELS spectra.

DSSCs with the Alumina Particles Wrapped in Graphene Sheets. The graphene- $\mathrm{TiO}_{2}$ composite mesoporous film was prepared by paint shaking and dispersing the alumina particles wrapped in graphene sheets ( $1 \mathrm{wt} \%)$ and commercial $\mathrm{TiO}_{2}(\mathrm{P} 25)$ nanoparticles together in ethanol. The graphene$\mathrm{TiO}_{2}$ colloid was thoroughly dispersed using a conditioning mixer by adding ethyl cellulose as a binder and $\alpha$-terpineol as a solvent for the graphene- $\mathrm{TiO}_{2}$ paste, after which the mixture was concentrated using an evaporator. An $18 \mu \mathrm{m}$ thick, mesoporous graphene- $\mathrm{TiO}_{2}$ layer was prepared by doctor-blading the graphene- $\mathrm{TiO}_{2}$ paste on the fluorinedoped tin oxide (FTO) transparent conducting oxide (TCO), followed by calcination at $450{ }^{\circ} \mathrm{C}$ for $30 \mathrm{~min}$. For comparison, an $18 \mu \mathrm{m}$-thick, mesoporous $\mathrm{TiO}_{2}$ layer without the graphene sheets was also prepared. The photoanodes were immersed in ethanol solution of $\mathrm{N} 3$ dye overnight for dye-adsorption, rinsed with ethanol, and dried at $50{ }^{\circ} \mathrm{C}$.

The DSSCs with and without the alumina particles wrapped in graphene sheets were prepared with a platinum counter electrode and an electrolyte composed of 0.6 M 3-hexyl-1,2dimethyl imidazolium iodide, $0.05 \mathrm{M}$ iodine, $0.05 \mathrm{M}$ LiI, and $0.5 \mathrm{M}$ 4-tert-butylpyridine in acetonitrile. The photovoltaic characteristics of the DSSCs were measured under 1 sunlight intensity $\left(100 \mathrm{~mW} \mathrm{~cm}^{-2}, \mathrm{AM} 1.5\right)$ that was verified with an AIST-calibrated Si-solar cell (PEC-L11, Peccell Technologies, Inc.).

\section{Results and Discussion}

The black powders were obtained by calcining AIN powders (Figure $1(\mathrm{a})$ ) at $1400{ }^{\circ} \mathrm{C}$ for 5 and $20 \mathrm{~h}$ under a flow of 10 vol\% CO/Ar. The XRD pattern (Fig. 1(b)) of the sample obtained after $5 \mathrm{~h}$ (hereafter referred to as Sample A) exhibited weak diffraction peaks assigned to $\delta-\mathrm{Al}_{2} \mathrm{O}_{3}$ (JCPDS Card No. 46-1131), together with diffraction peaks assigned to AIN (JCPDS Card No. 25-1133). In the XRD pattern (Fig. 1(c)) of the sample obtained after $20 \mathrm{~h}$ (hereafter referred to as Sample B), peaks assigned to $\mathrm{AlN}, \delta-\mathrm{Al}_{2} \mathrm{O}_{3}$, and $\alpha-\mathrm{Al}_{2} \mathrm{O}_{3}$ (JCPDS Card No. 46-1212), were detected. The carbon content in Samples A and B was 2.7 and 5.2 weight $\%$, respectively, indicating that the black color of the two samples was due to the carbonaceous material they contained. The observation of $\mathrm{Al}_{2} \mathrm{O}_{3}$ and carbon in the product powders indicated that the reverse reaction of Eq. (1) occurred at $1400{ }^{\circ} \mathrm{C}$. We recently showed that the CRN reaction of $\mathrm{Al}_{2} \mathrm{O}_{3}$ under a mixed gas flow of $\mathrm{CO}$ and $\mathrm{N}_{2}$ becomes more retarded with increasing $\mathrm{CO}$ content. ${ }^{24}$ The retardation effect of $\mathrm{CO}$ on the $\mathrm{CRN}$ reaction indicated the occurrence of the reverse reaction of Eq. (1).

No diffraction peaks assigned to the carbonaceous material were detected, as shown in Figures 1(b) and (c). In order to identify the carbonaceous material, we measured the Raman spectra of the product powders. Raman spectroscopy is one of the most powerful characterization tools for carbonaceous

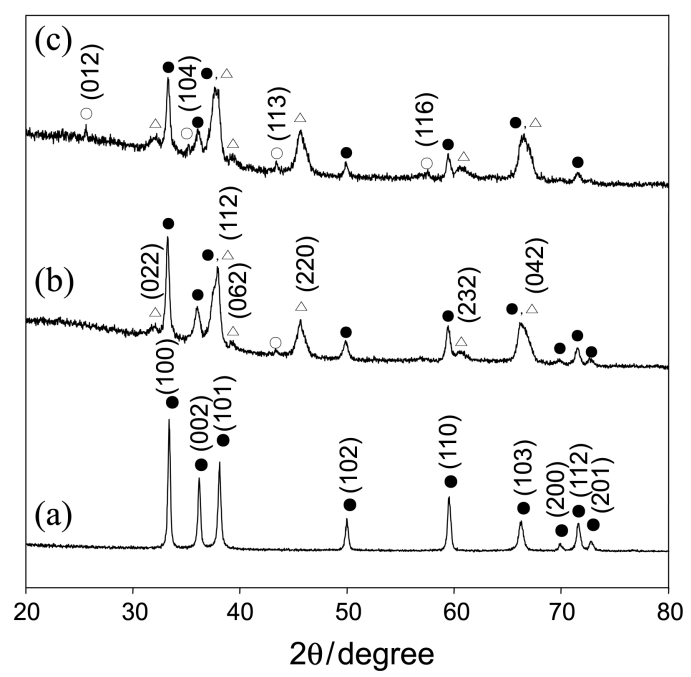

Figure 1. XRD patterns of powders obtained by the calcination of (a) AIN powder at $1400{ }^{\circ} \mathrm{C}$ for (b) 5 and (c) $20 \mathrm{~h}$ under a flow of 10 vol \% CO/Ar. (•) AlN, (○) $\alpha-\mathrm{Al}_{2} \mathrm{O}_{3},(\triangle) \delta-\mathrm{Al}_{2} \mathrm{O}_{3}$.
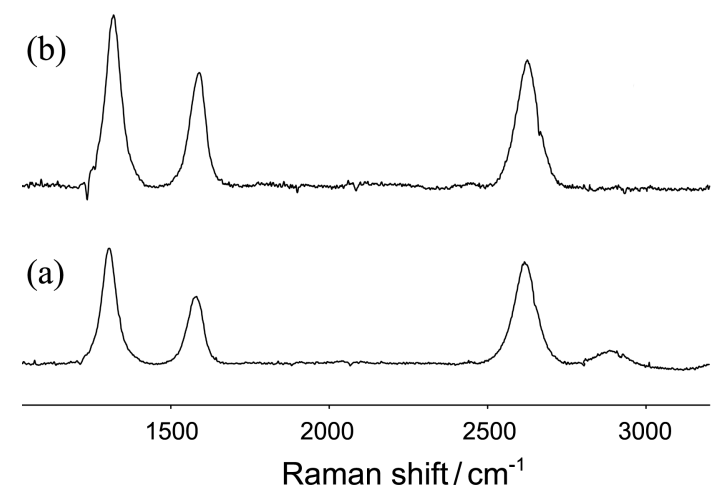

Figure 2. Raman spectra of powders obtained by calcination of AlN powder at $1400{ }^{\circ} \mathrm{C}$ for (a) 5 and (b) $20 \mathrm{~h}$ under a flow of 10 vol \% CO/Ar.

materials such as two-dimensional graphene sheets and one-dimensional carbon nanotubes. ${ }^{25}$ As shown in Figure 2, the Raman spectra of Samples A and B exhibited three characteristic bands of graphene sheets: D (at 1314 and 1317 $\mathrm{cm}^{-1}$ for Samples A and B, respectively), $\mathrm{G}$ (at $1588 \mathrm{~cm}^{-1}$ for both samples), and 2D $\left(2614 \mathrm{~cm}^{-1}\right.$ and $2624 \mathrm{~cm}^{-1}$ for Samples A and B, respectively). The weak and broad band at $2870 \mathrm{~cm}^{-1}$ in Figure 2(a) was assigned to the D + G combination band. In our previous study, the graphene sheets prepared by the reaction of $\mathrm{CO}$ with $\mathrm{Al}_{2} \mathrm{~S}_{3}$ in the temperature range $800-1100{ }^{\circ} \mathrm{C}$ did not exhibit their characteristic XRD peaks but did show intense D, G, and 2D bands in the Raman spectra. ${ }^{15}$ Therefore, the absence of any diffraction peaks assigned to the graphene sheets in Figures 1(b) and (c) was ascribed to the small number of graphene layers and/or the low crystallinity of the graphene sheets. ${ }^{15}$ The $\mathrm{D}$ band is due to the breathing modes of $\mathrm{sp}^{2}$ atoms in rings. In general, the $\mathrm{D}$ band, which has often been observed for graphene sheets prepared by chemical reactions, ${ }^{26-28}$ is related to the occurrence of defects and structural disorder in graphene sheets. ${ }^{25}$ The 
$\mathrm{G}$ band corresponds to the $E_{2 g}$ phonon at the Brillouin zone center. The intensity ratio of the $\mathrm{D}$ band to the $\mathrm{G}$ band slightly decreased with increasing duration because of the reduced degree of defects and structural disorder in the graphene sheets. ${ }^{29}$ The reduction was also indicated by the disappearance of the $\mathrm{D}+\mathrm{G}$ combination band, which is induced by disorder, ${ }^{29}$ as shown in Figure 2(b).

The band pattern of the Raman spectrum (Fig. 2(a)) of Sample A was similar to that of the graphene sheets (hereafter referred to as Sample $\mathrm{C}$ ) that we previously obtained by calcination of $\mathrm{Al}_{2} \mathrm{~S}_{3}$ at $1100{ }^{\circ} \mathrm{C}$ for $10 \mathrm{~h}$ under a flow of $10 \mathrm{vol} \% \mathrm{CO} / \mathrm{Ar}^{15}$ Comparing the positions of bands D, G, and $2 \mathrm{D}$ between Samples A and C, the position of the D band was similar in both samples, but the position of the $G$ band was blue-shifted by $\sim 17 \mathrm{~cm}^{-1}$, while the position of the $2 \mathrm{D}$ band was red-shifted by $\sim 20 \mathrm{~cm}^{-1}$. The origin of the blue shift of the $G$ band remains unclear but may have originated from the strain effect caused by the interaction between $\mathrm{Al}_{2} \mathrm{O}_{3}$ and graphene sheets. Wang et al. investigated the effect of substrates on the Raman spectrum of monolayer graphene. ${ }^{30}$ The positions of the $\mathrm{G}$ and $2 \mathrm{D}$ bands were negligibly affected by substrates for the graphene prepared by mechanically cleavage of graphite, but were significantly blue-shifted for the epitaxially grown graphene on $\mathrm{SiC}^{30}$ They interpreted the blue shift in terms of the strain effect caused by the covalent bonding between $\mathrm{SiC}$ substrate and graphene. On the other hand, the red shift of the 2D band may be explained by a combination of effects caused by the strain and layer number. Considering that the position of the $2 \mathrm{D}$ band is red-shifted with decreasing number of layers of graphene sheets, ${ }^{25}$ and given the very few layers in Samples $\mathrm{A}$ and $\mathrm{B}$ (see below), the red shift of the 2D band indicates that the strain effect may be overwhelmed by the effect of the layer number.

The graphene sheets in Sample B were characterized by HRTEM, operated at $80 \mathrm{kV}$. We previously reported that the graphene sheets obtained by the reaction of $\mathrm{Al}_{2} \mathrm{~S}_{3}$ with $\mathrm{CO}$ were silk-like, ${ }^{14,15}$ but those in Sample B were not. Four parallel dark fringes were observed at the edge of the Sample B particles, as shown in Figure 3(a). The spacing between the neighboring fringes was $0.34 \mathrm{~nm}$, which was consistent with the spacing between the (002) planes of graphite. The EELS spectra in the carbon K-edge were also measured to ensure that the fringes were derived from graphene sheets. EELS is a powerful method to reveal the detailed structures and has been used largely to research amorphous and nanocrystalline carbon films. ${ }^{31}$ As shown in Figure 3(b), the EELS spectrum for the fringes (spot a) in Fig. 3(a)) showed the feature of a graphite EELS spectrum in the carbon K-edge region. The peaks at 287 and $294 \mathrm{eV}$ correspond to transitions from the $1 \mathrm{~s}$ to the $\pi^{*}$ and $\sigma^{*}$ states, respectively. The EELS spectrum for the upper surface (spot (b) in Fig. 3(a)) also exhibited the feature of a graphite EELS spectrum. The EELS spectra of Figure 3(b) indicated that few-layer graphene sheets wrapped around alumina particles. This wrapping may induce an interaction between the graphene sheets and alumina that causes the blue shift of the
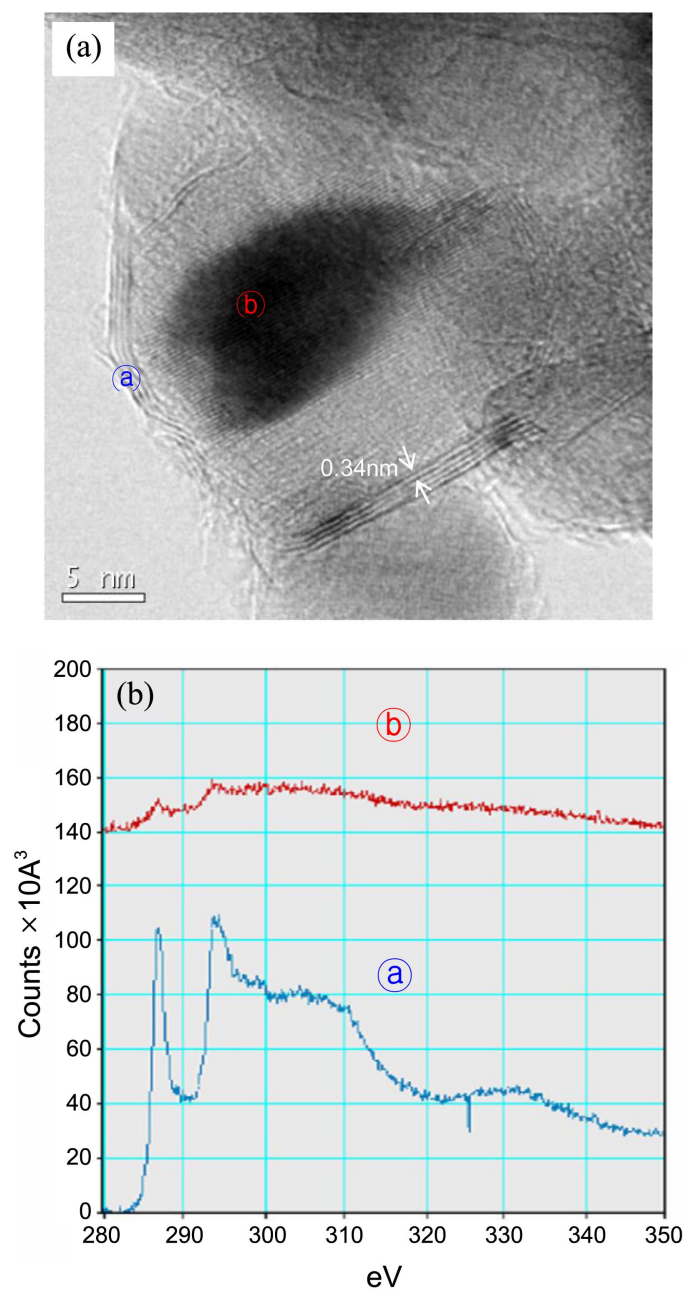

Figure 3. HRTEM image and EELS spectra of the powder obtained by calcination of AIN powder at $1400{ }^{\circ} \mathrm{C}$ for $20 \mathrm{~h}$ under a flow of $10 \mathrm{vol} \% \mathrm{CO} / \mathrm{Ar}$.

$\mathrm{G}$ band in the Raman spectrum. ${ }^{30}$

The graphene sheets were formed by the reaction of $\mathrm{CO}$ with AIN in the reverse reaction of Eq. (1), in which CO is reduced to gaseous carbon, which subsequently crystallized in the graphene sheets, while AIN was converted to $\delta-\mathrm{Al}_{2} \mathrm{O}_{3}$ and subsequently transformed into $\alpha-\mathrm{Al}_{2} \mathrm{O}_{3}$. Incomplete conversion of $\mathrm{AIN}$ to $\mathrm{Al}_{2} \mathrm{O}_{3}$ in this study was attributed to the wrapping of graphene sheets, which hindered the diffusion of $\mathrm{CO}$ into the inner side of the AlN particles. In our previous investigation on the reduction of $\mathrm{CO}$ by $\mathrm{Al}_{2} \mathrm{~S}_{3},{ }^{15} \mathrm{Al}_{2} \mathrm{~S}_{3}$ was completely converted to $\mathrm{Al}_{2} \mathrm{O}_{3}$ at $1400{ }^{\circ} \mathrm{C}$ due to the absence of any wrapping of the graphene sheets.

Figure 4 shows the photocurrent-voltage curves of the DSSCs without and with the alumina particles wrapped in few-layer graphene sheets. The DSSC with the graphene$\mathrm{TiO}_{2}$ composite electrode exhibited an $11 \%$ increase in higher overall energy conversion efficiency from 4.6 to $5.1 \%$. The amount of the dye adsorbed in the $1 \mathrm{wt} \%$ graphene$\mathrm{TiO}_{2}$ film was slightly lower than that of the $\mathrm{TiO}_{2}$ film. The graphene-incorporated $\mathrm{TiO}_{2}$ films could, however, significantly enhance the electron lifetime, the details of which are described elsewhere. ${ }^{32}$ Therefore, the significantly improved 


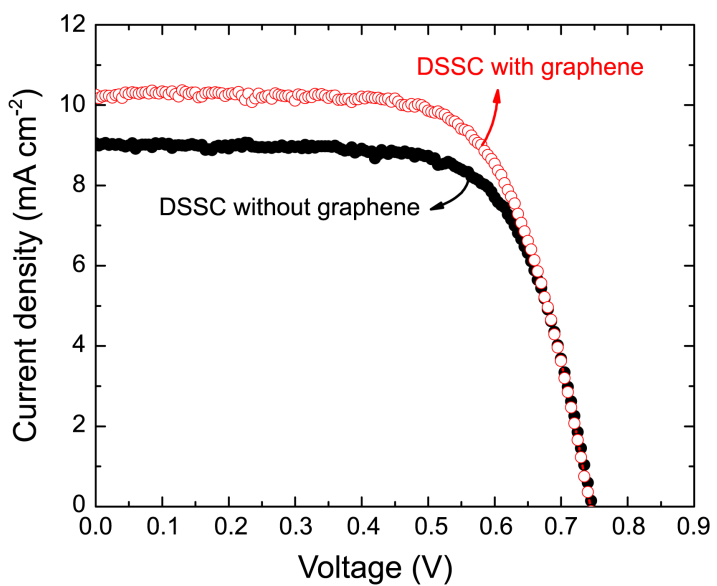

Figure 4. Photocurrent-voltage curves of the DSSCs with and without the alumina particles wrapped in graphene sheets. The active area was $0.24 \mathrm{~cm}^{2}$.

cell performance of the DSSC with the graphene- $\mathrm{TiO}_{2}$ composite electrode can be attributed to the reduced recombination rate caused by the longer electron lifetime.

\section{Conclusions}

This work has presented a method for the synthesis of alumina particles wrapped in few-layer graphene sheets by the reduction of $\mathrm{CO}$. The $\mathrm{CO}$ was reduced to gaseous carbon by the reaction of AIN, which is the reverse reaction of the CRN reaction of alumina. The gaseous carbon crystallized in the graphene sheets. Few-layer graphene sheets, which wrapped around alumina particles, did not exhibit diffraction peaks in the XRD patterns but did show three characteristic D, G, and 2D bands in the Raman spectra. The positions of the $G$ and $2 D$ bands were different from those of the freestanding graphene sheets. The DSSC using $\mathrm{TiO}_{2}$ nanoparticles mixed with alumina particles wrapped in few-layer graphene sheets exhibited significantly improved energy conversion efficiency, compared to the conventional DSSC, due to the reduced recombination rate caused by the enhanced electron lifetime.

Acknowledgments. This work is supported by the Ministry of Education, Science \& Technology (MEST) and the National Research Foundation of Korea (NRF) under a "Human Resource Development Center for Economic Region Leading Industry" Project. One of the authors (WSJ) is grateful to Professor Bongsoo Kim, KAIST, Korea, for measuring the Raman spectra.

\section{References}

1. Novoselov, K. S.; Geim, A. K.; Morozov, S. V.; Jiang, D.; Zhang,
Y.; Dubonos, S. V.; Grigorieva, I. V.; Firsov, A. A. Science 2004, $306,666$.

2. Novoselov, K. S.; Geim, A. K.; Morozov, S. V.; Jiang, D.; Katsnelson, M. I.; Grigorieva, I. V.; Dubonos, S. V.; Firsov, A. A. Nature 2005, 438, 197.

3. Katsnelson, M. I. Materialstoday 2007, 10, 20.

4. Stankovich, S.; Dikin, D. A.; Dommett, G. H. B.; Kohlhaas, K. M.; Zimney, E. J.; Stach, E. A.; Piner, R. D.; Nguyen, S. T.; Ruoff, R. S. Nature 2006, 442, 282.

5. Gómez-Navarro, C.; Burghard, M.; Kern, K. Nano Lett. 2008, 8, 2045.

6. Stankovich, S.; Piner, R. D.; Chen, X. Q.; Wu, N. Q.; Nguyen, S. T.; Ruoff, R. S. J. Mater. Chem. 2006, 16, 155.

7. Stankovich, S.; Dikin, D. A.; Piner, R. D.; Kohlhaas, K. A.; Kleinhammes, A.; Jia, Y.; Wu, Y.; Nguyen, S. T.; Ruoff, R. S. Carbon 2007, 45, 1558.

8. Wang, G.; Yang, J.; Park, J.; Gou, X.; Wang, B.; Liu, H.; Yao, J. J. Phys. Chem. C 2008, 112, 8192.

9. Kudin, K. N.; Ozbas, B.; Schiepp, H. C.; Pruïhomme, R. K.; Aksay, I. A.; Car, R. Nano Lett. 2008, 8, 36.

10. Berger, C.; Song, Z.; Li, T.; Li, X.; Ogbazghi, A. Y.; Feng, R.; Dai, Z.; Marchenkov, A. N.; Conrad, E. H.; First, P. N.; De Heer, W. A. J. Phys. Chem. B 2004, 108, 19912.

11. Ohta, T.; Bostwick, A.; Seyller, T.; Horn, K.; Rotenberg, E. Science 2006, 313, 951.

12. Wang, J. J.; Zhu, M. Y.; Outlaw, R. A.; Zhao, X.; Manos, D. M.; Holloway, B. C. Appl. Phys. Lett. 2004, 85, 1265.

13. Dato, A.; Radmilovic, V.; Lee, Z.; Phillips, J.; Frenklach, M. Nano Lett. 2008, 8, 2012.

14. Kim, C.-D.; Min, B.-K.; Jung, W.-S. Carbon 2009, 47, 1610.

15. Yoon, I.; Kim, C.-D.; Min, B.-K.; Kim, Y.-K.; Kim, B.; Jung, W.S. Bull. Korean Chem. Soc. 2009, 30, 3045.

16. Selvadruray, G.; Sheet, L. Mater. Sci. Technol. 1993, 9, 463.

17. O'Regan, B.; Grätzel, M. Nature 1991, 353, 737.

18. Kang, S.-H.; Choi, S.-H.; Kang, M.-S.; Kim, J.-Y.; Kim, H.-S.; Hyeon, T.; Sung, Y.-E. Adv. Mater. 2008, 20, 54.

19. Ahn, K.-S.; Kang, M.-S.; Lee, J.-K.; Shin, B.-C.; Lee, J.-W. Appl. Phys. Lett. 2006, 89, 013103.

20. Archer, M. D.; Nozik, A. J. Nanostructured and PhotoelectroChemical Systems for Solar Photon Conversion; Imperial College Press: Singapore, 2008.

21. Sun, S.; Gao, L.; Liu, Y. Appl. Phys. Lett. 2010, 96, 083113.

22. Yang, N.; Zhai, J.; Wang, D.; Chen, Y.; Jiang, L. ACS Nano 2010, $4,887$.

23. Jung, W.-S. Bull. Korean Chem. Soc. 2009, 30, 1563.

24. Joo, H. Y.; Jung, W.-S. J. Mater. Proc. Technol. 2008, 204, 498.

25. Ferrari, A. C. Solid State Commun. 2007, 143, 47.

26. Wang, J. J.; Zhu, M. Y.; Outlaw, R. A.; Zhao, X.; Manos, D. M.; Holloway, B. C.; Mammana, V. P. Appl. Phys. Lett. 2004, 85, 1265.

27. Dato, A.; Radmilovic, V.; Lee, Z.; Phillips. J.; Frenklach, M. Nano Lett. 2008, 8, 2012.

28. Wang, G.; Yang, J.; Park, J.; Gou, X.; Wang, B.; Liu, H.; Yao, J. J. Phys. Chem. C 2008, 112, 8192.

29. Pimenta, M. A.; Dresselhaus , G.; Dresselhaus, M. S.; Cançado, L. G.; Jori, A.; Saito, R. Phys. Chem. Chem. Phys. 2007, 9, 1276.

30. Wang, Y. Y.; Ni, Z. H.; Yu, T.; Shen, Z. X.; Wang, H. M.; Wu, Y. H.; Chen, W.; Wee, A. T. S. J. Phys. Chem. C 2008, 112, 10637.

31. Chu, P. K.; Li, L. Mater. Chem. Phys. 2006, 96, 253.

32. Park, J.-H.; Seo, S.-W.; Kim, J.-H.; Choi, C.-J.; Kim, H.-S.; Lee, D. K.; Jung, W.-S.; Ahn, K.-S. Mol. Cryst. Liq. Cryst. 2011, in press. 